OPEN ACCESS

Edited by:

Cheryl J. Craig,

Texas A\&M University, United States

Reviewed by:

Balwant Singh,

Partap College of Education, India

Jason DeHart

Appalachian State University,

United States

*Correspondence:

Wing Yee Lo

winnielo@wsu.ac.kr

Specialty section:

This article was submitted to

Teacher Education

a section of the journal

Frontiers in Education

Received: 15 January 2021

Accepted: 02 March 2021

Published: 24 March 2021

Citation:

Lo WY (2021) Public Health

and Early Childhood Education: An

Analysis of Chinese Pre-service

Teachers' Reflections During

the COVID-19 Pandemic.

Front. Educ. 6:654097.

doi: 10.3389/feduc.2021.654097

\section{Public Health and Early Childhood Education: An Analysis of Chinese Pre-service Teachers' Reflections During the COVID-19 Pandemic}

Wing Yee Lo*

Department of Early Childhood Education, Woosong University, Daejeon, South Korea

The purpose of this study was to investigate Chinese pre-service kindergarten teachers' beliefs and behaviors inherent to a public health perspective in the time of coronavirus disease (COVID-19) pandemic. The study intended to deepen our understanding of the contextual factors that may influence their future implementation of public health education in early childhood settings. Forty-five participants were recruited from an early childhood teacher education program, with the majority $(n=41)$ reporting that they lived through the strict restrictions in different regions of China during the initial COVID-19 outbreak. Data were collected via a reflective writing task from an online course. The results indicated an increasing awareness of public health among the participants due to the COVID-19 crisis. Their personal hygiene behaviors included personal protection, cleaning, disinfection, physical distancing, avoidance, and ventilation. The pandemic also changed pre-service teachers' beliefs about the importance of public health education. Although the participants seemed to have positive attitudes toward public health education, evidence of their limitations of knowledge and skills was further exposed in their ideas for teaching health-related topics. When there is a need to strengthen public health education in the ongoing fight against COVID-19, this paper calls for a refocus in pre-service teacher education to improve public health outcomes for young children.

Keywords: China, COVID-19, early childhood education, pre-service kindergarten teachers, public health, reflective practice, teacher education

\section{INTRODUCTION}

The novel coronavirus disease (COVID-19, formerly known as 2019-nCoV) has rapidly spread around the world since first being recorded in late December 2019 in Wuhan, the capital city of Hubei Province in China (Zhang et al., 2020). As of January 15, 2021, according to the Center for Systems Science and Engineering at Johns Hopkins University (Dong et al., 2020), nearly two million deaths have been reported across 191 countries from over 93 million cases of COVID-19. In response to this enduring public health emergency, World Health Organization (WHO) has issued a series of guidance on public health and social measures to reduce the risk of COVID-19 transmission (e.g., World Health Organization, 2020a,c). 
Education plays a crucial role of preventive measures in coping with the new normal imposed by COVID-19 (Van den Broucke, 2020). Early childhood education can provide young children with a foundation for healthy development. Therefore, kindergarten teachers are encouraged to focus on the promotion of good health behaviors and simple public health interventions in order to engage students aged three to six on preventing the spread of infectious diseases (World Health Organization, 2020 b). To ensure the long-run success of age-specific health education, teacher preparation is a key concern in maintaining and enhancing the public health learning environment.

The literature presents various definitions of the term "public health," owing to its complexity associated with cultural sensitivity (Resnicow et al., 1999; Parmet, 2009). It is conventionally accepted that the notion of public health is concerned with "the prevention of disease and disability, and the promotion of the health of the public" (Liamputtong, 2019, p. 16). In 1920, Winslow (1920) at Yale University clearly defined public health as the science and art of three elements involving "preventing disease, prolonging life, and promoting physical health" (p. 183) via a community effort. Although his description of public health was articulated a century ago, it continues to have a profound impact on today's public health objectives. In order to capture the public health challenges in the 21st century, researchers at Durham University and WHO Europe (Marks et al., 2011) extracted the definitions of public health used by major stakeholders in the health sector and provided an summary of public health concepts for content analysis. Their results showed that 13 out of the 15 selected definitions, including one adopted by World Health Organization, (2011), were derived from Winslow (1920).

In reviewing the more recent literature on public health, the disciplines of public health usually involve epidemiology, biostatistics, environmental and occupational health sciences, social and behavioral sciences, assessment and policy development, and health services administration (Schneider, 2017; Liamputtong, 2019). The overall objective of public health is to apply science to prevent disease, improve longevity, and promote physical and mental well-being among the population as a whole (Arab et al., 2014). Since the emergence of severe acute respiratory syndrome (SARS) in 2003, followed by Middle East respiratory syndrome (MERS) in 2012 and the current COVID-19 pandemic (Zhu et al., 2020), there has been a growing interest in public health education.

In China, public health education was traditionally viewed as a discipline of preventive medicine (Bangdiwala et al., 2011; Jin et al., 2020). Over time it has evolved into a strategy for "ensuring and promoting public health" (Wu and Li, 2017, p. 1894). The past two decades have witnessed an expansion of university programs in China at both undergraduate and postgraduate levels to address the national demand for well-trained public health professionals (Hou et al., 2018). During the COVID-19 pandemic, the importance of public health has been highlighted in Chinese early childhood settings (Ministry of Education of the People's Republic of China, 2020). However, the discussions have largely been confined school-related public health measures rather than to issues of education. This might not help improve sustainability of public health interventions in the long run (Walugembe et al., 2019).

Public health education has a moral significance (Lee and Royo-Bordonada, 2015; Tulchinsky et al., 2015; Gordijn, 2017; Specker and Schermer, 2017). It relates to ethical obligations and personal moral conscience. There are many university programs in public health emphasizing on the development of competencies pertaining to individual attributes such as knowledge, skills, and attitudes through a variety of self-assessment methods (Czabanowska et al., 2014). These reflective practices can inspire university students to think deeply about the specific content of critical incidents in their learning portfolios (Biggs and Tang, 2011). Reflection is also a common component in teacher training programs because it can serve as a means to enhance professional growth by challenging pre-service teachers' pre-existing knowledge and beliefs (Korthagen and Vasalos, 2005; Williams and Power, 2009; Shandomo, 2010).

The primary goal of this study was to gain insight into the perceptions and experiences of Chinese pre-service kindergarten teachers as documented in their reflections on public health education in the context of COVID-19. The study was guided by the following research questions:

(1) What is the nature of Chinese pre-service kindergarten teachers' prior knowledge in public health?

(2) How do Chinese pre-service kindergarten teachers' awareness and beliefs about public health education change during the COVID-19 pandemic?

(3) What are Chinese pre-service kindergarten teachers' personal health behaviors during the COVID-19 pandemic?

(4) To what extent do the Chinese pre-service teachers are prepared to promote public health in early childhood education?

Understanding the belief change and hygiene behaviors of pre-service teachers amidst the pandemic can make a significant contribution to the development of initial teacher education in public health. There is a lack of research on the link between public health and early childhood education in China. The current study can contribute to an emerging body of research into public health education. The findings of the study have much wider significance for the reform of teacher education to prepare pre-service teachers to become health education professionals at the kindergarten level.

\section{METHOD}

This was a qualitative study with a cross-sectional design to explore Chinese pre-service kindergarten teachers' beliefs about public health education and their hygiene behaviors at the early stage of the COVID-19 pandemic. A reflection task was utilized as the research instrument in the study. 


\section{Participants}

The voluntary participants of the study were 45 Chinese international students enrolled in the bachelor's degree program in early childhood education at a university in South Korea. These pre-service kindergarten teachers were recruited from an online class for both third and final year students. There were 40 females and 5 male participants, and their ages ranged from 20 to 25 years. At the time of the data collection, 41 participants reported that they were in seven different regions of China (28 in Jiangsu Province, seven in Anhui Province, two in Zhejiang Province, one each in Guizhou Province, Hebei Province, Hubei Province, and Shanghai) while others remained in South Korea.

\section{The Instrument and Data Collection}

Reflection is of common use in teacher education. Reflective learning is a mechanism to turn pre-service teachers' experiences as well as their pre-exiting knowledge and beliefs into learning. Synthesizing the models of reflection used in the previous research into pre-service teachers' beliefs and practices (e.g., Ditchburn, 2015; Sheridan, 2016; Arslan, 2019; Oonk et al., 2020), three facets of reflective learning have been identified. The first step is to look back on the past. The second step is to understand the present. The final step is to make plans for the future. These dynamic processes of reflection have informed the approach taken in the current study.

This study employed a reflective writing task which consisted of three sections involving different question items to obtain a general picture of participants' health-related beliefs and behaviors. The first two sections addressed the changes in pre-service teachers' awareness and beliefs regarding public health during the COVID-19 period as compared to before the pandemic. Besides, the participants also had to recall what they had learnt about public health at school in the first section, and reflect on their own hygiene behaviors amidst the COVID19 outbreak in the second section. Section three required the participants to think about what actions they would take in their future teaching to enhance the public health learning environment for young children.

Data collection was conducted in March 2020 while WHO declared the epidemiology of COVID-19 outbreak a global pandemic (Liu et al., 2020). With the first semester of the academic year 2020 starting online, all the Chinese pre-service kindergarten teachers from Years 3 and 4 were invited to complete the reflective writing task in an English online class of professional studies.

\section{Data Analysis}

In the study, data obtained from the reflective writing task were analyzed in an inductive manner (Guest et al., 2012). With the assistance of NVivo software package (Paulus and Lester, 2020), a data-driven strategy for generating categories was adopted in the qualitative content analysis. As pre-service teachers' responses to each section of the reflection task were written in English, no translation was needed. It could reduce the risk of data analysis mistakes.

\section{RESULTS}

\section{Prior Knowledge in Public Health}

In the first section of the reflection task, there was a question item addressing participants' past school learning experiences on the topic of public health. Based on the responses to this question, pre-service teachers' prior knowledge in public health was classified into six domains: personal hygiene habits, environment education, preventive healthcare, healthy lifestyle, food safety, and ventilation. Among the 45 pre-service teachers, only three claimed that they did not learn anything about public health at school. An example of a response for each domain of public health knowledge is provided in Table 1.

In addition, 10 responses were considered unclear, for example, "safety" and "campus security". Altogether 86 responses were collected from 42 participants while 32 responses were referred to as the domain of personal hygiene habits and 17 responses were identified as belonging to the domain of environmental education. No more than 10 responses were classified into each of the four other public health knowledge domains. It should be noted that many participants only mentioned one or two knowledge domains in their reflections. These findings affirmed that many pre-service teachers appeared to possess limited knowledge of public health prior to their teacher training.

\section{Changes in Public Health Awareness and Beliefs}

Two set of questions focused on participants' affective perceptions of public health in the first and the second sections of the reflective writing task. Frequency analysis was applied to data obtained from these questions in order to compare pre-service teachers' levels of public health awareness and their beliefs about

TABLE 1 | Examples for pre-service teachers' prior knowledge in public health.

\begin{tabular}{ll}
\hline Public health knowledge domain & Selected response of pre-service teachers \\
\hline Personal hygiene habits & No spitting on the floor. \\
Environmental education & No littering. I also learned how to classify wastes as recyclable and non-recyclable. \\
Preventive healthcare & In the event of new epidemics, I can protect myself from infection by washing hands and wearing a face mask. \\
Healthy lifestyle & We should not smoke. We should have a healthy and balanced diet. \\
Food safety & It is not good to eat street food. \\
Ventilation & Our classrooms should be well-ventilated.
\end{tabular}


the importance of public health education before and during the COVID-19 pandemic.

\section{Public Health Awareness}

Based on Freud's (1915) theory of the division of consciousness, three levels of awareness were used to describe participants' public health awareness in the study. Pre-service teachers' responses reflecting their awareness about public health were categorized as "consciousness," "unconsciousness," or "preconsciousness." Table 2 shows the comparison of their public health awareness before and during the COVID-19 pandemic.

It is not surprising to find that all the participating preservice teachers demonstrated a high level of awareness about public health during the pandemic. However, about $42 \%$ of them ( $n=19$ ) had paid no attention to it before the pandemic hit. Of the 45 participants, 12 had not been aware of public health, and 7 readily recalled their memories of public health events in the reflection task but they had never thought of that in the past (see Table 2).

\section{Beliefs About the Importance of Public Health Education}

All 45 pre-service teachers realized the importance of public health during the COVID-19 outbreak. More than half of them $(n=26)$ agreed on its importance even before the pandemic. The participants provided different reasons to explain why they held such beliefs between these two periods. The responses reflecting their beliefs about the importance of public health education were classified into nine categories as shown in Table 3.

In the period before the COVID-19 outbreak, the preservice teachers believed that public health education was importance because it played a major role in communicable disease prevention. Some participants' responses referred to their experiences gained from SARS in 2003. The following direct quotation is an example:

Our country had experienced SARS when I was very young. Since then, I've already realized the importance of public health education. [...] At school, I think students should learn how to prevent infectious diseases.

Apart from communicable disease prevention, other factors such as hygiene promotion, civic responsibility, health-related quality of life, self-care in health, as well as wildlife and environmental protection were also considered by the pre-service

TABLE 2 | Comparison of pre-service teachers' public health awareness before and during the COVID-19 pandemic.

\begin{tabular}{lcc}
\hline Public Health Awareness & \multicolumn{2}{c}{ Frequency $^{a}$} \\
\cline { 2 - 3 } & Before COVID-19 & During COVID-19 \\
\hline Consciousness & 26 & 45 \\
Unconsciousness & 12 & 0 \\
Pre-consciousness & 7 & 0
\end{tabular}

alt refers to the number of participants whose responses are included in that category $(n=45)$.
TABLE 3 | Comparison of pre-service teachers' beliefs about the importance of public health education before and during the COVID-19 pandemic.

Beliefs about the
Importance of Public

Frequency $^{a}$

Health Education

\begin{tabular}{|c|c|c|}
\hline & \\
\hline & Before COVID-19 & During COVID-19 \\
\hline $\begin{array}{l}\text { Communicable disease } \\
\text { prevention }\end{array}$ & 10 & 30 \\
\hline Self-care in health & 2 & 14 \\
\hline Civic responsibility & 5 & 7 \\
\hline Hygiene promotion & 7 & 5 \\
\hline $\begin{array}{l}\text { Wildlife and environmental } \\
\text { protection }\end{array}$ & 1 & 4 \\
\hline Health-related quality of life & 3 & 2 \\
\hline Access to healthcare & 0 & 1 \\
\hline $\begin{array}{l}\text { Development of positive } \\
\text { attitudes toward healthcare } \\
\text { professional }\end{array}$ & 0 & 1 \\
\hline
\end{tabular}

alt refers to the number of responses are included in that category.

teachers to explain the importance of public health education prior to the COVID-19 crisis.

During the COVID-19 period, many pre-service teachers deemed public health education important because of its potential contribution to disease prevention and health promotion. The results presented in Table 3 indicated that more responses were grouped into the category of communicable disease prevention, for instance, "prevention is better than cure." At the same time, there was a great increase in the number of responses which were classified as the category of self-care in health, for example, "public health education is concerned about everyone's health." The findings also revealed that more participants than ever before regarded wildlife and environmental protection as a part of public health education.

\section{Personal Health Behaviors Amidst the COVID-19 Outbreak}

In section two of the reflection task, the participants were required to reflect on their personal hygiene behaviors amidst the pandemic. Fifteen subcategories emerged from an analysis of their responses to the question item regarding their current hygiene practices at the time of the reflections. These subcategories were identified as belonging to six categories. The categories were labeled as personal protection, cleaning, disinfection, physical distancing, avoidance, and ventilation (see Table 4).

In Table 4, most of the responses were categorized as two types of personal hygiene behaviors: personal protection and cleaning. "Wearing face masks in public spaces" and "washing hands frequently" were the dominant hygiene practices among the pre-service teachers. Disinfection was another personal hygiene behavior of the participants, but they seemed to prefer using household disinfectants to using alcohol-based hand sanitizers. Other hygiene behaviors during the COVID-19 pandemic including physical distancing, avoidance, and ventilation were 
also mentioned in their reflections. Nonetheless, no participant acknowledged manners and social etiquette (such as no shaking hands) as his or her current hygiene behavior amidst the COVID19 outbreak.

\section{Approaches to Promoting Public Health in Early Childhood Education}

The final section of the reflective writing task provided the pre-service teachers with an opportunity to demonstrate their readiness and capacity to promote public health in kindergarten classrooms. They were asked to articulate their teaching ideas in this section. It aimed to explore to what extent the pre-service teachers developed their competencies in public health education.

The findings showed that the participants were willing to spend time and effort to prepare themselves for teaching young children about public health. Most of them claimed that they would put children's health and safety first in their future teaching. The following quotations are the examples to illustrate their positive attitudes toward public health education:

I will study hard to equip myself with the knowledge required for carrying out public health learning activities in kindergarten.

When I become a kindergarten teacher after the pandemic, I will still remember children's health is a top priority. I will teach them how to protect themselves from viruses.

TABLE 4 | Categorization of pre-service teachers' current personal hygiene behaviors.

\begin{tabular}{|c|c|c|c|}
\hline Category & Subcategory & Frequency $^{a}$ & Total \\
\hline \multirow[t]{2}{*}{$\begin{array}{l}\text { Personal } \\
\text { protection }\end{array}$} & $\begin{array}{l}\text { Wearing face masks in public } \\
\text { spaces }\end{array}$ & 33 & 37 \\
\hline & $\begin{array}{l}\text { Use of other personal protective } \\
\text { equipment (such as hygiene gloves) }\end{array}$ & 4 & \\
\hline \multirow[t]{2}{*}{ Cleaning } & Washing hands frequently & 33 & 36 \\
\hline & $\begin{array}{l}\text { Taking shower and change after } \\
\text { coming back home }\end{array}$ & 3 & \\
\hline \multirow[t]{2}{*}{ Disinfection } & Use of household disinfectants & 20 & 26 \\
\hline & $\begin{array}{l}\text { Use of alcohol-based hand } \\
\text { sanitizers }\end{array}$ & 6 & \\
\hline \multirow[t]{4}{*}{$\begin{array}{l}\text { Physical } \\
\text { distancing }\end{array}$} & $\begin{array}{l}\text { Reducing the frequency of going } \\
\text { out }\end{array}$ & 7 & 14 \\
\hline & Staying at home & 4 & \\
\hline & $\begin{array}{l}\text { Keeping a safe distance from } \\
\text { others }\end{array}$ & 2 & \\
\hline & No large group indoor gatherings & 1 & \\
\hline \multirow[t]{4}{*}{ Avoidance } & Avoiding raw food or eating out & 6 & 12 \\
\hline & $\begin{array}{l}\text { Avoiding touching eyes, nose, and } \\
\text { mouth with contaminated hands }\end{array}$ & 2 & \\
\hline & $\begin{array}{l}\text { Avoiding directly touching public } \\
\text { surfaces and animals }\end{array}$ & 2 & \\
\hline & Avoiding crowded places & 2 & \\
\hline Ventilation & Ventilation in indoor environments & 6 & 6 \\
\hline
\end{tabular}

alt refers to the number of responses are included in that subcategory.
However, merely a small number of pre-service teachers were able to connect the early childhood curriculum with their teaching ideas. Most of them focused on guiding children to develop good personal hygiene habits, such as washing hands before eating. They could suggest some public health learning activities suitable for young children but many decided to use "telling" as the only teaching strategy. Of the 45 pre-service teachers, only four planned to use "games" as a teaching method to promote public health in kindergarten. These findings revealed that the pre-service teachers had limited knowledge and skills for public health education practice in the context of early learning.

\section{DISCUSSION}

As found in this study, the COVID-19 pandemic has had a considerable impact on the beliefs and behaviors of the Chinese pre-service kindergarten teachers. Data analysis also revealed a tendency to support constructive beliefs about the importance of public health education due to COVID-19. This global health crisis has made the participating pre-service teachers more aware of public health. These findings support those of Zhong et al. (2020), indicating that a large proportion of Chinese residents strictly followed hygiene practices to prevent COVID19 transmission. They claimed that most respondents of their online survey research were knowledgeable about COVID-19. Their findings also indicated that $98 \%$ of the sampled Chinese residents wore face masks in public places during the pandemic. This is in concordance with the results of the current study in which many pre-service teachers mentioned about wearing face masks as one of their current personal hygiene behaviors in the reflection task.

Even though manners and social etiquette (such as performing respiratory etiquette when coughing or sneezing) are included in guidelines provided by the Chinese government (Yoo et al., 2020), it is interesting to note that less attention has been paid to this specific hygiene practice in the Chinese society. In the present study, the Chinese pre-service teachers did not mention it when they reflected on their personal hygiene behaviors. Only one pre-service teacher considered teaching children manners and social etiquette to prevent the spread of diseases in the future. This would imply that the pre-service teachers might miss some important public health topics in the kindergarten classroom when their content knowledge is limited. Thus, it is advised that early childhood teacher education programs should equip pre-service kindergarten teachers with a better understanding of public health practices. Teacher educators need to consider cultural and social factors when conducting public health courses for pre-service teachers.

In relation to competencies in public health education, it was found that the participating pre-service teachers generally demonstrated positive attitudes toward public health education. However, their limited knowledge and skills likely inhabit the implementation of public health education in early childhood settings. The results indicated that many pre-service teachers preferred using a teacher-centered approach to teaching the health-related topics in the future. In teaching public health, 
"it is very important to transfer not only knowledge but experiences to the students that can lead them to take action in their communities" (Marin-Kelso, 2013, p. 710). Therefore, teacher educators have to develop pre-service teachers' pedagogical skills to help their future students learn better in an interactive learning environment.

In future research, face-to-face or online in-depth interviews with the Chinese pre-service kindergarten teachers could be considered. This may allow the pre-service teachers to further elaborate on their responses to the reflection task. It would also help researchers to further infer pre-service teachers' beliefs about public health. Besides, a longitudinal study could be used in future studies because pre-service teachers' health-related beliefs and behaviors may change after their graduation. The Chinese in-service kindergarten teachers' competencies in public health education is worthy of further investigation.

\section{CONCLUSION}

Training early childhood professionals from non-health backgrounds to do public health education is an innovation in the field of teacher education. It is believed that the reform requires considerable time and effort. In order to strengthen public health education to improve global health, it is essential to start promoting health and wellbeing as well as preventing disease from the kindergarten level. Public health education not only contains health education but also civic and moral education. This is a challenge for the early childhood teacher education program to prepare pre-service teachers to take an additional

\section{REFERENCES}

Arab, C., Antunes, T. P. C., de Almeida Barbosa, R. T., Crocetta, T. B., Bezerra, I. M. P., and Ferreira, C. (2014). Review of "Oxford textbook of public health". J. Hum. Growth Dev. 24, 361-362. doi: 10.7322/jhdg. 88978

Arslan, F. Y. (2019). Reflection in pre-service teacher education: exploring the nature of four EFL pre-service teachers' reflections. Reflective Pract. 20, 111124. doi: 10.1080/14623943.2018.1564652

Bangdiwala, S. I., Tucker, J. D., Zodpey, S., Griffiths, S. M., Li, L.M., Reddy, K. S., et al. (2011). Public health education in India and China: history, opportunities, and challenges. Public Health Rev. 33, 204-224.

Biggs, J., and Tang, C. (2011). Teaching for Quality Learning at University, 4th Edn. Buckingham: The Society for Research into Higher Education \& Open University Press.

Czabanowska, K., Malho, A., Schröder-Bäck, P., Popa, D., and Burazeri, G. (2014). Do we develop public health leaders? - Association between public health competencies and emotional intelligence: a cross-sectional study. BMC Med. Educ. 14:83. doi: 10.1186/1472-6920-14-83

Ditchburn, G. M. (2015). Remembering reflection in pre-service teachers' professional experience. Aust. J. Teach. Educ. 40, 94-111. doi: 10.14221/ajte. $2015 \mathrm{v} 40 \mathrm{n} 2.7$

Dong, E., Du, H., and Gardner, L. (2020). An interactive web-based dashboard to track COVID-19 in real time. Lancet Infect. Dis. 20, 533-534. doi: 10.1016/ S1473-3099(20)30120-1

Freud, S. (1915). "The unconscious," in The Standard Edition of the Complete Psychological Works of Sigmund Freud, ed. J. Strachey (London: Hogarth), $166-215$. role as public health educators in kindergartens. The COVID-19 pandemic is a human tragedy. To prevent the next global health emergency, educators, researchers, and curriculum developers now need to turn the threat of COVID-19 into an opportunity to enhance public health.

\section{DATA AVAILABILITY STATEMENT}

The original contributions presented in the study are included in the article/supplementary material, further inquiries can be directed to the corresponding author.

\section{ETHICS STATEMENT}

Ethical review and approval was not required for the study on human participants in accordance with the local legislation and institutional requirements. The patients/participants provided their written informed consent to participate in this study.

\section{AUTHOR CONTRIBUTIONS}

The author was responsible for the writing of the manuscript.

\section{FUNDING}

This work was supported by Woosong University Academic Research Funding 2021.

Gordijn, B. (2017). Commentary: reservations about the lessons drawn from moral education, public health ethics, and forensic psychiatry. Camb. Q. Healthc. Ethics 26, 427-430. doi: 10.1017/S0963180116001092

Guest, G., MacQueen, K., and Namey, E. (2012). Applied Thematic Analysis. Thousand Oaks, CA: USA: Sage.

Hou, J., Wang, Z., Liu, X., Luo, Y., Sabharwal, S., Wang, N., et al. (2018). Public health education at China's higher education institutions: a time-series analysis from 1998 to 2012. BMC Public Health 18:679. doi: 10.1186/s12889-018-5605-4

Jin, H., Dong, G., Zou, L., Shen, X., and Li, D. (2020). History and status quo of higher public health education in China. Public Health Rev. 41, 1-16. doi: 10.1186/s40985-020-00120-x

Korthagen, F., and Vasalos, A. (2005). Levels in reflection: core reflection as a means to enhance professional growth. TTTP 11, 47-71. doi: 10.1080/ 1354060042000337093

Lee, L. M., and Royo-Bordonada, M. A. (2015). Continuing the conversation about public health ethics: education for public health professionals in Europe. Public Health Rev. 36:5. doi: 10.1186/s40985-015-0001-4

Liamputtong, P. (2019). "Public health: an introduction to local \& global perspectives," in Public Health: Local \& Global Perspectives, ed. P. Liamputtong (Melbourne, VIC: Cambridge University Press), 1-21.

Liu, Y. C., Kuo, R. L., and Shih, S. R. (2020). COVID-19: the first documented coronavirus pandemic in history. Biomed. J. 43, 328-333. doi: 10.1016/j.bj.2020. 04.007

Marin-Kelso, C. (2013). "Communicating, motivating and teaching the significance of public health," in Current Topics in Public Health, ed. A. J. Rodriguez-Morales (Rijeka: InTech), 709-730.

Marks, L., Hunter, D. J., and Alderslade, R. (2011). Strengthening Public Health Capacity And Services in Europe: A Concept Paper. Copenhagen: World Health Organization Regional Office for Europe. 
Ministry of Education of the People's Republic of China. (2020). Guidelines on COVID-19 Prevention and Control in Kindergartens. Beijing: People's Medical Publishing House.

Oonk, W., Verloop, N., and Gravemeijer, K. P. E. (2020). Analyzing student teachers' use of theory in their reflections on mathematics teaching practice. MERJ 32, 563-588. doi: 10.1007/s13394-01900269-y

Parmet, W. E. (2009). Populations, Public Health, And The Law. Washington, DC: Georgetown University Press.

Paulus, T. M., and Lester, J. N. (2020). "Using software to support qualitative data analysis," in Handbook of Qualitative Research in Education, eds M. R. M. Ward and S. Delamont (Cheltenham: Edward Elgar Publishing Limited), 420-429.

Resnicow, K., Baranowski, T., Ahluwalia, J. S., and Braithwaite, R. L. (1999). Cultural sensitivity in public health: defined and demystified. Ethn Dis 9, 10-21.

Schneider, M. J. (2017). Introduction to Public Health, 5th Edn. Burlington, MA: Jones \& Bartlett Learning.

Shandomo, H. M. (2010). The role of critical reflection in teacher education. Sch. Univ. Partnersh. 4, 101-113.

Sheridan, L. (2016). Examining changes in pre-service teachers' beliefs of pedagogy. Aust. J. Teach. Educ. 41, 1-20. doi: 10.14221/ajte.2016v41n3.1

Specker, J., and Schermer, M. H. N. (2017). Imagining moral bioenhancement practices: drawing inspiration from moral education, public health ethics, and forensic psychiatry. Camb. Q. Healthc. Ethics 26, 415-426. doi: 10.1017/ S0963180116001080

Tulchinsky, T., Jennings, B., and Viehbeck, S. (2015). Integrating ethics in public health education: the process of developing case studies. Public Health Rev. 36:4. doi: 10.1186/s40985-015-0002-3

Van den Broucke, S. (2020). Why health promotion matters to the COVID-19 pandemic, and vice versa. Health Promot. Int. 35, 181-186. doi: 10.1093/heapro/ daaa042

Walugembe, D. R., Sibbald, S., Le Ber, L. M., and Kothari, A. (2019). Sustainability of public health interventions: where are the gaps? Health Res. Policy Syst. 17:8. doi: 10.1186/s12961-018-0405-y

Williams, J., and Power, K. (2009). "Using core reflection in teacher education," in Paper Presented at the 'Teacher Education Crossing Borders: Cultures, Contexts, Communities And Curriculum' The Annual Conference Of The Australian Teacher Education Association (ATEA), Albury.

Winslow, C. E. A. (1920). The untilled fields of public health. Mod Med 2, 183-191.
World Health Organization. (2011). Glossary of Globalization, Trade and Health Terms. Geneva: WHO.

World Health Organization. (2020a). Considerations for Implementing and Adjusting Public Health and Social Measures in the Context of COVID-19: Interim Guidance, 4 November 2020. Geneva: WHO.

World Health Organization. (2020b). Key Messages And Actions For COVID-19 Prevention And Control in Schools, March 2020. Geneva: WHO.

World Health Organization. (2020c). Overview of Public Health and Social Measures in The Context of COVID-19: Interim Guidance, 18 May 2020. Geneva: WHO.

Wu, T., and Li, L. (2017). Evolution of public health education in China. Am. J. Public Health 107, 1893-1895. doi: 10.2105/AJPH.2017.304110

Yoo, J. Y., Dutra, S. V. O., Fanfan, D., Sniffen, S., Wang, H., Siddiqui, J., et al. (2020). Comparative analysis of COVID-19 guidelines from six countries: a qualitative study on the US, China, South Korea, the UK, Brazil, and Haiti. BMC Public Health 20:1853. doi: 10.1186/s12889-020-09924-7

Zhang, L., Li, H., and Chen, K. (2020). Effective risk communication for public health emergency: reflection on the COVID-19 (2019-nCoV) outbreak in Wuhan. China Healthc. 8:64. doi: 10.3390/healthcare8010064

Zhong, B. L., Luo, W., Li, H. M., Zhang, Q. Q., Liu, X. G., Li, W. T., et al. (2020). Knowledge, attitudes, and practices towards COVID-19 among Chinese residents during the rapid rise period of the COVID-19 outbreak: a quick online cross-sectional survey. Int. J. Biol. Sci. 16, 1745-1752. doi: 10.7150/ijbs.45221

Zhu, Z., Lian, X., Su, X., Wu, W., Marraro, G. A., and Zeng, Y. (2020). From SARS and MERS to COVID-19: a brief summary and comparison of severe acute respiratory infections caused by three highly pathogenic human coronaviruses. Respir. Res. 21:224. doi: 10.1186/s12931-020-01479-w

Conflict of Interest: The author declares that the research was conducted in the absence of any commercial or financial relationships that could be construed as a potential conflict of interest.

Copyright (c) 2021 Lo. This is an open-access article distributed under the terms of the Creative Commons Attribution License (CC BY). The use, distribution or reproduction in other forums is permitted, provided the original author(s) and the copyright owner(s) are credited and that the original publication in this journal is cited, in accordance with accepted academic practice. No use, distribution or reproduction is permitted which does not comply with these terms. 